\title{
La imagen femenina en tiempos del \#metoo: publicidad de moda, perfume y cosmética
}

\section{Female image the time of \#metoo: fashion, perfume, and cosmetic advertisements}

\author{
Doris Treviños-Rodríguez; Paloma Díaz-Soloaga
}

Cómo citar este artículo:

Treviños-Rodríguez, Doris; Díaz-Soloaga, Paloma (2021). “La imagen femenina en tiempos del \#metoo: publicidad de moda, perfume y cosmética". Profesional de la información, v. 30, n. 2, e300205.

https://doi.org/10.3145/epi.2021.mar.05

Artículo recibido el 06-05-2020

Aceptación definitiva: 15-08-2020

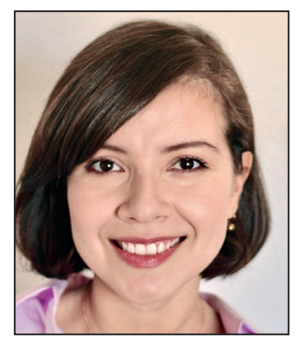
Doris Treviños-Rodríguez $\bowtie$ https://orcid.org/0000-0002-0465-0604
Doctoranda en Universidad Complutense de Madrid
Facultad de Ciencias de la Información
Av. Complutense, 3
28040 Madrid, España
doristre@ucm.es

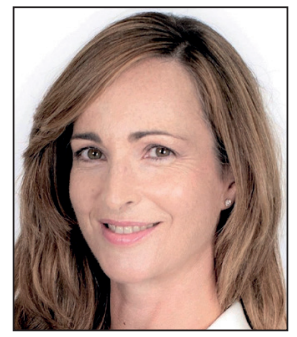

\section{Paloma Díaz-Soloaga}

https://orcid.org/0000-0003-1798-1768

Universidad Complutense de Madrid

Facultad de Ciencias de la Información

Av. Complutense, 3

28040 Madrid, España

pdiaz@ucm.es

\section{Resumen}

Esta investigación analiza los estereotipos femeninos presentes en anuncios gráficos de marcas de lujo de moda, perfume y cosmética en España. Se identifican, también, estereotipos de belleza con los que se representa a las mujeres. Este trabajo empírico es una continuación de los estudios que Díaz-Soloaga viene realizando desde 2005, analizando la evolución en la representación de la mujer en la publicidad gráfica. Se llevó a cabo un análisis de contenido de 168 anuncios publicados en las cabeceras de moda Elle, Glamour, Telva, Vogue y Woman Madame Figaro. Como principal resultado se obtuvieron seis perfiles femeninos muy similares a los identificados en anteriores estudios, al tiempo que se confirmó la permanencia de los estereotipos de belleza. Aunque se observan avances, la publicidad gráfica de marcas de lujo de moda, perfume y cosmética continúa mostrando modelos que contribuyen a alimentar una imagen inexacta de la mujer. Resulta paradójico que, en el contexto de reivindicación femenina actual, en lugar de empoderar a su audiencia las cabeceras de moda contribuyan a encasillarla en una imagen dependiente, narcisista y muy sexualizada.

\section{Palabras clave}

Mujer; Estereotipos; Revistas de moda; Publicidad gráfica; Marcas; Moda; Perfume; Cosmética; Análisis de contenido.

\begin{abstract}
This research analyzes the female stereotypes presented in graphic advertisements for luxury fashion, perfume, and cosmetic brands in Spain. It identifies the beauty stereotypes with which women are portrayed. This empirical work represents a continuation of the studies carried out by Díaz-Soloaga since 2005, to analyze the evolution of the representation of women in graphic advertising. Content analysis of 168 advertisements published in the fashion titles Elle, Glamour, Telva, Vogue, and Woman Madame Figaro was carried out. The main result was the observation of six female profiles that are remarkably similar to those identified in previous studies, thus confirming the permanence of the same beauty stereotypes. Although some progress is observed, advertising of luxury fashion, perfume, and cosmetic brands continues to display stereotypes that contribute to an inaccurate image of women. It is paradoxical that, in the context of current feminine demands, instead of empowering their audience, fashion magazines contribute to their pigeonholing using dependent, narcissistic, and highly sexualized images.
\end{abstract}

\section{Keywords}

Women; Stereotypes; Fashion magazines; Graphic advertising; Brands; Fashion; Perfume; Cosmetics; Content analysis. 


\section{Introducción}

El notorio despunte del movimiento feminista en los últimos años ha abierto nuevamente la polémica sobre el valor de la mujer en la sociedad actual. Ahora el debate parece haberse agudizado en torno a la mujer como víctima de abusos, entre los que destacan el acoso, el abuso sexual y la trata de mujeres. Casos de gran repercusión como el del tráfico y explotación sexual de mujeres capitaneado por el financiero estadounidense Jeffrey Epstein, o la revelación de los abusos sexuales acometidos por el productor cinematográfico Harvey Weinstein, sentenciado a 23 años de prisión (CNN, 2020), han contribuido a fortalecer esta tendencia. Al involucrar a rostros conocidos del mundo del entretenimiento, personalidades influyentes e incluso miembros de la realeza (Pozzi, 2019), estos sucesos han acaparado la atención mediática internacional provocando una serie de reacciones críticas.

A raíz de estos acontecimientos se han alzado voces de protesta que gracias a las nuevas tecnologías han conseguido propagarse con mayor éxito, dando lugar al nacimiento o resurgimiento de fenómenos como el \#metoo (yo también, en castellano). Dicho fenómeno, que sitúa su origen en 2006 como una forma de dar voz y presencia mediática a las mujeres afroamericanas en Estados Unidos, reapareció en 2017 como un hashtag que invitaba a todas las mujeres a compartir sus historias de acoso sexual, con motivo del escándalo desencadenado por Harvey Weinstein (Muñoz-Saavedra, 2019).

En España también se han compartido y denunciado casos de violencia sexual. Sin embargo, en nuestro país el \#metoo aúna la lucha contra todos los abusos (violencia de género, violencia sexual, brecha laboral, desigualdad de género, etc.) de los que son víctimas las mujeres, y que han arrastrado a lo largo del tiempo (Arriaza-lbarra; Berumen, 2019). Tal ha sido el alcance de este movimiento que algunos autores piensan que el mundo estaría asistiendo al comienzo de la cuarta ola del feminismo (Muñoz-Saavedra, 2019).

En vista de todos estos sucesos, puede que sea de nuevo el momento de preguntarse ¿qué importancia se concede socialmente a la mujer?; ¿por qué se siguen cometiendo atropellos en contra de su integridad?; ¿cuál es la imagen de mujer que se proyecta en los medios?; ¿cuál es el ideal de mujer que se maneja y se reproduce?; ¿se corresponde esta representación mediática y publicitaria con la realidad de sus vidas y aspiraciones? Posiblemente algunas de las respuestas se encuentren en el hecho de que las mujeres no se han liberado de ciertos estereotipos dañinos que les impiden desenvolverse como desearían.

\section{Estado de la cuestión}

El movimiento \#metoo ha puesto sobre la palestra mundial el problema de la violencia sexual contra las mujeres. Alrededor del mundo las experiencias compartidas con el hashtag \#metoo se han centrado en narrar episodios de acoso sexual en el entorno laboral donde un hombre ostentaba el poder (Jaffe, 2018). Así, el abuso de poder, que se materializa en violencia, refleja la desigualdad de género que subyace en la sociedad (Jaffe, 2018), problemática que la rama española del \#metoo se ha propuesto especialmente combatir (Arriaza-Ibarra; Berumen, 2019).

Esta desigualdad de género también se percibe en los estereotipos asignados a mujeres y hombres. Sin duda, esas

“imágenes idealizadas, que pertenecen al imaginario colectivo y que son fácilmente identificables" (Berganza-Conde; Hoyo-Hurtado, 2006, p. 162),

constituyen para la mujer una pesada carga. Esta reflexión también engloba a los rasgos de belleza externa que suelen acompañar a los estereotipos de género (Vega-Saldaña; Barredo-lbáñez; Merchán Clavellino, 2019b). Al igual que ocurre con tales estereotipos de género, los de belleza imponen sobre todo la delgadez, la perfección del cuerpo y la juventud como las características físicas idóneas que una mujer debe poseer (Díaz-Soloaga; Quintas-Froufe; Muñiz, $2010 b)$.

Habría que comenzar por decir que los estereotipos sobreviven porque son atajos que la mente humana utiliza en su modo de conocer y simplificar la realidad (Fernández-Poncela, 2011). De alguna manera son un recurso práctico que nunca dejará de existir, puesto que son de gran ayuda a la hora de aprender y expresar aspectos complejos. Del mismo modo se puede decir que el estereotipo puede acercarse más o menos a la realidad que trata de simplificar. En ese punto es donde juegan un papel relevante los prejuicios, atribuciones negativas vinculadas a los estereotipos que refuerzan y cristalizan conceptos erróneos acerca de una determinada realidad.

La cuestión profunda, por tanto, no es si una determinada imagen estereotipada es buena o mala, sino más bien si dicho estereotipo se acerca o refleja bien la realidad, o se aleja de ella debido a los prejuicios hasta convertirse en una caricatura de lo que pretende representar. Con ese punto de partida se podría cuestionar si los estereotipos femeninos responden a conductas presentes en la sociedad, o si más bien los medios fomentan dichas conductas reforzándolas con sus constantes reproducciones hasta que consiguen imponerlas. Se trata por lo tanto de indagar en las distinciones entre lo masculino y lo femenino, tanto en la realidad como en la representación mediática de dicha realidad (Rodríguez; Pando-Canteli; Berasategi, 2016).

Cabría también preguntarse acerca de la finalidad de las publicaciones de moda y estilo de vida dirigidas al público femenino. ¿Su misión es la de educar y formar a las mujeres?, o ¿es más bien el entretenimiento, la evasión y la creación de sueños de belleza y glamur? De cómo se responda a estas preguntas se deriva un enfoque u otro de las representaciones femeninas que se incluyen entre sus páginas. Ahora bien, no se puede obviar que hoy y ahora las revistas no pueden escapar de su responsabilidad de formar a las mujeres acerca de su dignidad individual y de su rol social. 
Todo parece indicar que la presencia y la propagación de estos estereotipos obedece a la labor de reproducción y transmisión que ejercen los medios de comunicación y la publicidad (Martínez-Oña; Muñoz-Muñoz, 2015). Los medios de comunicación, con la finalidad de "informar y entretener defendiendo sus propios intereses", difunden al mismo tiempo una serie de estereotipos a sus audiencias (Aguaded; Valor-Rodríguez, 2011, p. 155). Por su parte, la publicidad, en su tarea de motivar la venta de un producto, se vale con frecuencia de los estereotipos,

"puesto que toda publicidad por definición es siempre o casi siempre estereotípica" (Navarro-Beltrá; Martín-Llaguno, 2011, p. 55).

Y, mediante una perspectiva marcada por el ideal de belleza socialmente aceptado (Zotos; Tsichla, 2014), se ha encargado de difundir la imagen de lo que significa ser mujer a través de las épocas (Martínez-Rodrigo, 2004).

La preocupación se acrecienta cuando se piensa en los estereotipos que exhiben los medios dirigidos al público femenino y la publicidad insertada en ellos. En este sentido, las revistas de moda y la publicidad que se encuentra en su interior son sin lugar a dudas el gran soporte comunicativo dirigido a la mujer (Gómez-de-Travesedo-Rojas; Almansa-Martínez, 2018). A través de lo que se publica en las páginas de estos medios es posible tener una idea de cómo es la mujer contemporánea (Vega-Saldaña; Barredo-Ibáñez; Merchán-Clavellino, 2019a).

En cuanto a los temas en los que se enfocan, destacan los que se consideran como de interés femenino: la moda y la belleza (Gómez-de-Travesedo-Rojas, 2015). Y de estas, las revistas de moda de alta gama son las que orientan más sus contenidos a temas de moda y belleza, al tiempo que se convierten en el escaparate preferido de la moda y la cosmética de lujo (Díaz-Soloaga; Muñiz-Muriel; Quintas-Froufe, 2010a). El consumo de estas revistas acerca a su público, las mujeres pertenecientes a las clases medias y altas (Gómez-de-Travesedo-Rojas, 2015), al mundo aspiracional del lujo que muchas de ellas ansían emular (Díaz-Soloaga et al., 2010a).

El hecho de conocer los estereotipos femeninos y de belleza que se manejan en la publicidad de moda, perfume y cosmética de lujo, un universo cargado de simbología, aspiración y fantasía, es de marcada importancia dado el impacto de dichas industrias. La realidad es que las investigaciones con ese objeto de estudio no son abundantes en España, y en el resto del mundo de habla hispana tampoco.

A pesar de ello, investigaciones como las de Pérez-Lugo, Gabino-Campos y Baile (2016), en México, presagian un futuro prometedor en esta línea de investigación. Haciendo un repaso por la bibliografía se advierte que el estudio de los estereotipos femeninos en medios impresos se remonta a la década de los setenta con Courtney y Lockeretz (1971). Posteriormente surgieron estudios similares hasta llegar a las investigaciones en revistas de moda, destacando estudios anglosajones y asiáticos.

En España se pueden destacar las investigaciones de Díaz-Soloaga (2007), Cáceres-Zapatero y Díaz-Soloaga (2008), Díaz-Soloaga et al. (2010a), Díaz-Soloaga et al. (2010b), Almansa-Martínez y Gómez-de-Travesedo-Rojas (2017), Treviños-Rodríguez y Díaz-Soloaga (2018), Vega-Saldaña et al. (2019a), Vega-Saldaña et al. (2019b) y Vega-Saldaña, Barredo-Ibáñez y Merchán-Clavellino (2020). En lo referido a los estereotipos de belleza, Díaz-Soloaga (2007) encontró que la mayoría de las mujeres de los anuncios eran rubias, blancas, jóvenes y de complexión delgada. Un año más tarde, Cáceres-Zapatero y Díaz-Soloaga (2008) descubrieron que los resultados no variaban. Asimismo, advirtieron que la presencia de mujeres negras, asiáticas y cobrizas no sumaban ni 5\% del total de la muestra analizada (Cáceres-Zapatero; Díaz-Soloaga, 2008). En 2010 un nuevo estudio de Díaz-Soloaga et al. (2010b) reafirmaba la blancura de la piel, el pelo rubio, la delgadez y la juventud como el estereotipo de belleza propuesto. Nueve años más tarde, las investigaciones de Treviños-Rodríguez y Díaz-Soloaga (2018) y Vega-Saldaña et al. (2019a) vieron que lo hallado en estudios anteriores permanecía constante, agregando estos últimos autores la variable altura como parte del estereotipo de belleza dominante. En otro artículo, Vega-Saldaña et al. (2019b) comprobaron que la delgadez continuaba perfilándose como un rasgo trascendente de la belleza femenina. En una reciente investigación, Vega-Saldaña et al. (2020) no han visto variaciones en los resultados.

En lo relativo a los estereotipos asociados a las actitudes y/o comportamientos, Díaz-Soloaga (2007) hablaba de la presencia de cinco estereotipos:

- mujer tradicional,

- mujer transgresora,

- mujer frágil o sometida,

- mujer hedonista-sensual, y

- mujer funcional-moderna.

Transcurridos tres años, Díaz-Soloaga et al. (2010a) descubrieron estereotipos similares:

- mujer luchadora-transgresora,

- mujer sensual,

- mujer tradicional,

- mujer pasiva, y

- mujer frágil. 
En 2017 Almansa-Martínez y Gómez-de-Travesedo-Rojas (2017) afirmaron que una mujer en el contexto del hogar ya no era común. De igual manera, repararon en la existencia de una nueva mujer que refleja amistad y afecto hacia su pareja sentimental (Almansa-Martínez; Gómez-de-Travesedo-Rojas, 2017).

Esa nueva mujer también fue detectada por Treviños-Rodríguez y Díaz-Soloaga (2018), que localizaron cuatro estereotipos:

- mujer moderna-transgresora,

- mujer familiar,

- mujer seductora, y

- mujer con éxito afectivo,

dejando atrás a las mujeres frágiles y pasivas. Precisamente para observar si ha habido alguna variación, el presente estudio se ha dispuesto a actualizar los resultados de este último trabajo.

El deseo de avanzar en una línea de investigación todavía poco explotada, unido al propósito de contribuir a que los estudios de moda ganen más peso en la academia son las principales motivaciones de esta investigación. A estas motivaciones también se suma la curiosidad por ver si un movimiento con gran eco mediático como el \#metoo ha conseguido hacer reflexionar a las marcas sobre el uso que hacen del cuerpo femenino en su publicidad.

\section{Objetivos y preguntas de investigación}

Como se ha dejado patente, el objeto de estudio que se aborda en este trabajo continúa siendo poco tratado por investigadores españoles y de habla hispana en general. Es por ello que el objetivo principal de este estudio consiste en actualizar los resultados de la investigación de Treviños-Rodríguez y Díaz-Soloaga (2018) sobre estereotipos femeninos, para observar si se han producido cambios en este nuevo escenario social y seguir alimentando esta línea de investigación. Saber cómo se representa físicamente a las mujeres en los anuncios de moda, perfume y cosmética de lujo, así como describir cuáles son los estereotipos femeninos presentes en esa clase de publicidad son los dos objetivos específicos que también se persiguen.

Puesto que el objetivo de este trabajo es actualizar los resultados del mencionado estudio de 2018, lo que conlleva la revisión de las hipótesis planteadas en el mismo, parece más conveniente establecer preguntas de investigación en lugar de nuevas hipótesis:

PI1: La mujer representada en la publicidad de moda, perfume y cosmética ¿mantiene desde hace más de una década el mismo perfil estereotipado que se recoge en el estudio de Díaz-Soloaga et al. (2010b): joven, blanca (caucásica), de rostro y cuerpo perfectos?

PI2: La presencia social del movimiento \#metoo ¿ha modificado los contenidos de la publicidad de moda, perfume y cosmética, o estos continúan mostrando a una mujer altamente sexualizada y seductora?

PI3: Aunque es posible ver a una mujer moderna y exitosa en los anuncios, ¿̇el movimiento \#metoo ha sido suficiente para lograr que esta se desmarque de los estereotipos que resaltan su belleza de manera primordial?

\section{Metodología}

Con la finalidad de cumplir los objetivos y responder a las preguntas de investigación planteadas, se decidió realizar un análisis de contenido cuantitativo. A través del análisis de contenido se puede extraer una información muy valiosa gracias a la interpretación de un texto, imagen, vídeo o audio, siempre que se haga con rigor

"nos abre las puertas al conocimiento de diversos aspectos y fenómenos de la vida social" (Andréu-Abela, 2001, p. 2).

La razón principal por la que se ha empleado este método es porque es el mejor modo que se conoce para investigar estereotipos en la publicidad gráfica, al identificar patrones muy difuminados entre los cientos de originales de las campañas de las marcas de moda, perfume y cosmética. Además, este estudio es una réplica de otros en los que se utilizaba esta misma técnica. Para actualizar los resultados de la última investigación de 2018, es necesario ceñirse a la misma metodología.

\subsection{Muestra}

Dado que se busca localizar y analizar estereotipos femeninos, la muestra debía estar compuesta por anuncios protagonizados por personajes femeninos. Quedaron fuera de la recopilación aquellos en los que aparecía solo un personaje masculino o el producto publicitado. También se eliminaron los anuncios duplicados. Finalmente, la muestra estuvo conformada por 168 anuncios de marcas de moda, perfume y cosmética de lujo. Estas piezas publicitarias fueron extraídas de cinco revistas de moda y belleza de alta gama, editadas y publicadas en España en los meses de agosto, septiembre y octubre de 2019.

Elle, Glamour, Telva, Vogue y Woman Madame Figaro fueron las cinco cabeceras de moda y belleza de las que se extrajeron los anuncios. La elección de las revistas se hizo en función de sus cifras de tirada, difusión y el número de lectores 
(tabla 1). Las cifras de tirada y difusión se obtuvieron de la Oficina de Justificación de la Difusión (OJD) para el periodo julio 2018/ junio 2019. Las cifras sobre el número de lectores se recopilaron a partir de los datos de la segunda ola de resultados del Estudio General de Medios (EGM).

La elección de los meses también obedeció a criterios imparciales. Septiembre es un mes importante para la industria de la moda y por extensión para las revistas de esta temática. A lo largo de ese mes las marcas presentan al mundo sus colecciones que posteriormente las revistas recogen. Al tratarse de uno de los números con mayor repercusión, las marcas buscan un lugar entre las páginas de estas cabeceras para anunciar sus productos, conscientes del alcance que tendrán. Por todo ello se vio oportuno elegir el mes de septiembre, al que se sumaron el mes anterior (agosto 2019) y el posterior (octubre 2019) para dotar de equilibrio al análisis.

Tabla 1. Difusión promedio, tirada promedio y lectores por mes.

\begin{tabular}{|l|c|c|c|}
\hline \multicolumn{1}{|c|}{ Revistas } & Difusión promedio & Tirada promedio & Lectores /mes (000) \\
\hline Elle & 82.177 & 128.242 & 539 \\
\hline Glamour & 100.748 & 192.911 & 408 \\
\hline Telva & 91.252 & 157.781 & 267 \\
\hline Vogue & 67.893 & 115.262 & 732 \\
\hline Woman Madame Figaro & 97.203 & 164.911 & 241 \\
\hline
\end{tabular}

Fuente: elaborado a partir de los datos de la OJD y el EGM:

https://www.ojd.es

http://reporting.aimc.es/index.htm/\#/main/revistas

\subsection{Libro de códigos y codificación}

La codificación de la muestra comenzó con la preparación del libro de códigos. Para este estudio no fue necesario elaborar uno nuevo. Se utilizó el mismo libro de códigos que en las investigaciones anteriores de Díaz-Soloaga, pero con algunos cambios. Se agregaron algunas variables y se eliminaron o modificaron otras, sumando en total 75 (siete independientes y 68 dependientes).

Estas variables quedaron distribuidas en cuatro apartados: datos generales del anuncio (seis variables), datos relacionados con el personaje analizado (29 variables), datos relativos a la apariencia estética de los personajes y/o textos (32 variables) y aspectos contextuales del anuncio (8 variables).

Cuando el libro de códigos estuvo listo comenzó la codificación, no sin antes asegurarse de que la interpretación de las imágenes por parte de las investigadoras de este estudio era la misma, realizando para ello un proceso de codificación conjunta. Aclarado este asunto, se procedió con la codificación definitiva. Por cada personaje femenino presente en los 168 anuncios de la muestra se abrió una ficha de análisis en la que se codificaron todas las variables. Los datos se reunieron en una hoja de cálculo Excel y posteriormente se volcaron en el programa SPSS versión 25 para someterlos a operaciones estadísticas.

Es importante señalar que, aunque se codificaron 75 items, en este estudio solo se comparten los resultados concernientes a los que se consideraron más relevantes para cumplir los objetivos y responder a las preguntas de investigación.

\section{Resultados}

\subsection{Resultados generales}

Antes de entrar en los estereotipos femeninos y la representación física de la mujer en esta clase de anuncios, es necesario conocer algunos datos generales a modo de contextualización. Como se había predicho, el análisis arrojó que más de la mitad de la muestra (53\%) pertenecía a revistas publicadas en el mes de septiembre de 2019.

Las revistas con mayor cantidad de anuncios extraídos fueron Vogue $(29,2 \%)$, Elle (28\%) y Telva (23,2\%). Glamour y Woman Madame Figaro solo albergaron el 10,7\% y 8,9\%, respectivamente. De las 168 piezas publicitarias analizadas, la mayoría anunciaban ropa (42,9\%) y complementos tales como bolsos, zapatos, relojes y cinturones $(38,1 \%)$.

Los productos cosméticos se anunciaron en un $9 \%$ de los anuncios seleccionados. Perfumes (6\%), joyería (3,6\%) y ropa interior $(0,6 \%)$ se posicionaron como los artículos menos anunciados de la muestra. Las marcas de lujo que publicitaron más sus productos fueron Chanel, Fendi, Dolce \& Gabbana, Guess, Gucci y Max Mara.

En cuanto a los personajes que aparecían en las piezas gráficas junto con los productos, la gran mayoría eran modelos, siendo el $78 \%$ no famosas y el $9,5 \%$ modelos conocidas. De todas ellas, el $82,7 \%$ tenían la apariencia de mujeres de clase alta y mostraban sobre todo el cuerpo entero $(57,1 \%)$, la zona del busto $(20,2 \%)$ y el rostro $(14,9 \%)$.

\subsection{Apariencia física de los personajes femeninos}

Se encontró que el 69,9\% de las figuras femeninas en las piezas publicitarias eran blancas, el 11,3\% se trataba de mujeres negras y un 7,7\% eran mujeres asiáticas. También se pudo observar que la presencia de mujeres rubias y morenas estuvo 
muy igualada. Si bien el porcentaje de mujeres rubias fue mayor $(38,7 \%)$, las mujeres morenas $(37,5 \%)$ estuvieron muy cerca de igualar o superar ese porcentaje. Las mujeres castañas y pelirrojas fueron representadas en un $13,1 \%$ y un $1,8 \%$ de las imágenes.

En lo referente a la complexión de las figuras femeninas, se reparó en que en estos anuncios predominaba la delgadez $(40,5 \%)$ y la delgadez extrema (25\%). Solo en siete anuncios se vio a una mujer saludable. Las mujeres más robustas fueron visibles únicamente en dos anuncios del total de la muestra. Por el contrario, las mujeres atléticas fueron visibles en el $91,1 \%$ de los casos.

Entrando en la edad de los personajes femeninos analizados, los resultados evidencian que las marcas de lujo de moda, perfume y cosmética tienen predilección por las mujeres de apariencia joven (de 15 a 30 años aproximadamente) para protagonizar sus anuncios. El 79,2\% de los personajes femeninos tenían aspecto juvenil, pero solo el 4,2\% parecía deliberadamente una menor de edad. Las mujeres adultas (de 30 a 65 años) estuvieron presentes en un 14,9\% y las mujeres mayores fueron casi inexistentes $(0,6 \%)$.

Independientemente de la edad, el 76,8\% de los personajes femeninos de todos los anuncios poseían un rostro perfecto $\sin$ muestras de cansancio y sin arrugas. En lo que respecta a las mujeres protagonistas de la publicidad de cosmética, el $80 \%$ de ellas mostraban un rostro perfecto.

\subsection{Estereotipos femeninos en la publicidad de moda, perfume y cosmética}

Una vez conocidos los datos sobre el perfil predominante en la apariencia física, fue momento de describir los estereotipos femeninos referentes a las actitudes y/o comportamientos de las mujeres. Para ello se llevó a cabo un análisis factorial con rotación ortogonal varimax que agrupó las variables en factores o clusters. Para este procedimiento se usaron 41 variables dicotómicas procedentes del segundo y tercer apartado del libro de códigos, las cuales habían sido codificadas con un " 1 " si el personaje las simbolizaba, o con un " 0 " si el personaje no las simbolizaba.

Tabla 2. Estereotipos presentes en la publicidad de marcas de lujo de moda, perfume y cosmética y las variables que los conforman. Segundo y definitivo análisis factorial.

\begin{tabular}{|c|c|c|c|c|c|c|}
\hline \multirow[b]{2}{*}{ Variables } & \multicolumn{6}{|c|}{ Estereotipos } \\
\hline & $\begin{array}{c}\text { Mujer } \\
\text { triunfadora }\end{array}$ & $\begin{array}{l}\text { Mujer } \\
\text { afectiva }\end{array}$ & $\begin{array}{c}\text { Mujer } \\
\text { seductora }\end{array}$ & $\begin{array}{l}\text { Mujer } \\
\text { familiar }\end{array}$ & $\begin{array}{l}\text { Mujer } \\
\text { moderna }\end{array}$ & $\begin{array}{l}\text { Mujer } \\
\text { agresiva }\end{array}$ \\
\hline $\begin{array}{l}\text { El personaje aparece tomando la iniciativa en la } \\
\text { relación que se refleja }\end{array}$ & 0,545 & & & & & \\
\hline Libertad & 0,663 & & & & & \\
\hline Esfuerzo personal & 0,731 & & & & & \\
\hline Triunfo & 0,764 & & & & & \\
\hline Éxito profesional & 0,734 & & & & & \\
\hline Competitividad & 0,712 & & & & & \\
\hline Alegría & & 0,703 & & & & \\
\hline Amistad & & 0,683 & & & & \\
\hline Éxito afectivo & & 0,605 & & & & \\
\hline Fidelidad & & 0,631 & & & & \\
\hline Seducción & & & 0,791 & & & \\
\hline Placer & & & 0,606 & & & \\
\hline Conquista & & & 0,838 & & & \\
\hline $\begin{array}{l}\text { El personaje aparece en actitud de seducción/ } \\
\text { galantería hacia otro }\end{array}$ & & & 0,587 & & & \\
\hline Amor & & & & 0,662 & & \\
\hline Familia & & & & 0,908 & & \\
\hline Atención al hogar & & & & 0,853 & & \\
\hline Violencia & & & & & & 0,746 \\
\hline Agresividad & & & & & & 0,796 \\
\hline Se muestran rasgos andróginos en el personaje & & & & & & 0,514 \\
\hline Transgresión & & & & & 0,742 & \\
\hline Riesgo & & & & & 0,564 & \\
\hline Modernidad & & & & & 0,719 & \\
\hline Porcentaje de la varianza & 20,05 & 14,59 & 9,62 & 7,71 & 6,68 & 5,04 \\
\hline Total & 63,69 & & & & & \\
\hline
\end{tabular}


Al efectuar el análisis se obtuvieron 11 factores que aglutinaban el 64,69\% de la varianza. Sin embargo, los factores resultantes eran muy numerosos. Con el objetivo de reducir los factores para poder explicar con claridad los estereotipos, se seleccionaron las variables con valores superiores a 0,5 que a su vez formaban parte de un factor compuesto por tres o más variables. Se seleccionaron 22 variables. Con estos items se ejecutó un segundo análisis factorial.

Los resultados de este segundo análisis arrojaron seis factores que aglutinaban el 63,69\% de la varianza. La prueba de esfericidad de Bartlett, con un Chi cuadrado $(253)=1523,80$ y significativa $(p \leq 0,001)$, junto con un índice KMO del 0,7 avalaron la garantía de este segundo análisis.

Así, fue posible afirmar que estos factores constituían seis estereotipos (tabla 2): mujer triunfadora, mujer afectiva, mujer seductora, mujer familiar, mujer moderna y mujer agresiva. Los estereotipos femeninos fueron nombrados de esa manera de acuerdo con las variables que les dieron forma.

La fiabilidad de los seis estereotipos se determinó midiendo el Alfa de Cronbach para cada uno de ellos: mujer triunfadora $(\alpha=0,828)$, mujer afectiva $(\alpha=0,682)$, mujer seductora $(\alpha=0,722)$, mujer familiar $(\alpha=0,666)$, mujer moderna ( $\alpha=$ 0,670 ) y mujer agresiva $(\alpha=0,558)$. Gracias a esta operación se comprobó que los estereotipos eran fiables.

Con el objetivo de saber qué estereotipo era el más recurrente, se calculó la media de cada uno. Previamente hubo que convertir a los estereotipos en variables. Los resultados mostraron que el estereotipo mujer moderna, con una media de 3,41 y una desviación típica de 3,59, se erigió como el estereotipo con más presencia. Por el contrario, el estereotipo mujer familiar con una media de 0,19 y una desviación típica de 1,08, se situó como el estereotipo menos frecuente (tabla 3).

Tabla 3. Medias y desviaciones típicas de los estereotipos femeninos

\begin{tabular}{|l|c|c|c|c|c|c|}
\hline \multirow{2}{*}{ Estadísticos } & \multicolumn{5}{|c|}{ Estereotipos } \\
\cline { 2 - 6 } & Mujer triunfadora & Mujer afectiva & Mujer seductora & Mujer familiar & Mujer moderna & Mujer agresiva \\
\hline Media & 3,38 & 1,37 & 1,58 & 0,19 & 3,41 \\
\hline Desviación típica & 3,34 & 2,46 & 2,63 & 1,08 & 3,59 \\
\hline
\end{tabular}

\subsection{Profundizando en los estereotipos femeninos}

El siguiente paso fue conocer en detalle los estereotipos para describirlos mejor. A partir de correlaciones bivariadas se examinó la relación de los seis estereotipos con 20 items usados para el análisis factorial, pero que no conformaban ningún factor, junto con cuatro variables correspondientes a la apariencia física de los personajes. Estas últimas eran variables con categorías, por lo tanto, hubo que convertir cada categoría en una variable apta para poder correlacionar.

A partir de estas correlaciones se vio que la mujer triunfadora (figura 1) se relaciona de forma muy significativa y positiva con mujeres adultas $(r=0,21, p \leq 0,05)$ que reflejan comodidad $(r=0,38, p \leq 0,001)$ y glamur $(r=0,31, p \leq 0,001)$. La pasividad $(r=-0,4, p \leq 0,001)$, sumisión $(r=-0,73, p \leq 0,001)$, languidez $(r=-0,32, p \leq 0,001)$, debilidad $(r=-0,6, p \leq$ $0,001)$, tristeza $(r=-0,35, p \leq 0,01)$ y fracaso $(r=-0,45, p \leq 0,001)$ no tienen cabida en la mujer triunfadora. No obstante, el valor estético del cuerpo es fundamental $(r=0,16, p \leq 0,05)$. En los anuncios en los que aparecen este tipo de mujeres se vincula directamente el aspecto bello del personaje con el consumo del producto $(r=0,25, p \leq 0,01)$. Las mujeres tienden a mostrar rostros y cuerpos perfectos $(r=0,22, p \leq 0,01)$.

La publicidad gráfica que reproduce el estereotipo de mujer afectiva (figura 2) exhibe una mujer cómoda consigo misma $(r=0,26, p \leq 0,01)$, expresiva $(r=0,37, p \leq 0,001)$ y que disfruta de las actividades de ocio $(r=0,19, p \leq 0,05)$. Una actitud pasiva $(r=-0,27, p \leq 0,001)$, la languidez $(r=-0,18, p \leq 0,05)$, debilidad $(r=-0,19, p \leq 0,05)$ y el fracaso $(r=-0,19, p \leq 0,05)$ tampoco forman parte de la personalidad de esta mujer. A diferencia de la mujer triunfadora, el aspecto físico ideal queda en un segundo plano, ya que la mujer afectiva posee una correlación positiva y muy significativa con una complexión

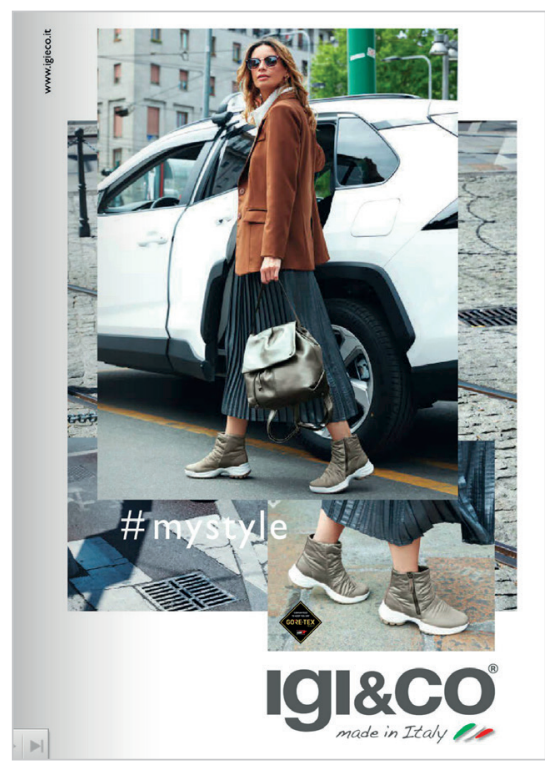

Figura 1. Mujer triunfadora. Fuente: revista Telva, septiembre 2019

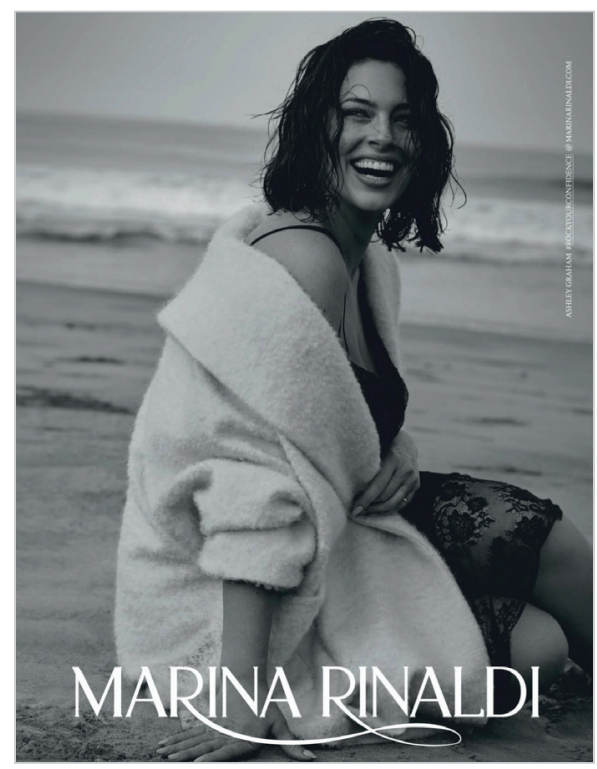

Figura 2. Mujer afectiva. Fuente: revista Elle, octubre 2019 
corporal más robusta $(r=0,27, p \leq 0,001)$, lo que no la exime de belleza y atractivo. De hecho, en los anuncios donde se puede ver a la mujer afectiva, también se relaciona directamente el aspecto bello del personaje con el consumo del producto $(r$ $=0,22, p \leq 0,01)$.

La mujer seductora (figuras 3 y 4 ) se muestra muy expresiva $(r=0,29, p \leq 0,001)$, al tiempo que transmite comodidad $(r=$ $0,38, p \leq 0,001)$, gozo $(r=0,27, p \leq 0,001)$ y atracción sexual $(r=0,4, p \leq 0,001)$. Puede decirse que es un estereotipo en el que no se encuentran actitudes como la languidez $(r=-0,21, p \leq 0,01)$, debilidad $(r=-0,3, p \leq$ $0,001)$, tristeza $(r=-0,22, p \leq 0,01)$ o fracaso $(r=-0,23, p \leq 0,01)$. Las piezas graficas que plasman este tipo de mujer ponen énfasis en asociar su belleza con el consumo del producto que anuncia $(r=0,41, p$ $\leq 0,001)$, representándola con un rostro y cuerpo perfectos $(r=0,25, p \leq 0,01)$.

En el caso del estereotipo mujer familiar (figura 5), se reparó en que las mujeres que se adscriben dentro de este clúster son adultas ( $r=0,18, p \leq 0,05)$, no aparecen en actitud pasiva y/o sumisa $(r=-0,17$, $p \leq 0,05)$ y el rostro perfecto no es su principal característica $(r=-0,16, p \leq 0,05)$.

La mujer moderna (figura 6) está significativamente asociada a mujeres que no expresan fracaso $(r=-0,30, p \leq 0,001)$, tristeza $(r=-0,22, p \leq 0,01)$, debilidad $(r=-0,37$, $p \leq 0,001)$ o un comportamiento pasivo $y / o$ sumiso $(r=-0,33, p \leq 0,001)$. También está ligada a mujeres atléticas $(r=0,23, p$ $\leq 0,01)$ con rostros y cuerpos perfectos $(r=$ $0,27, p \leq 0,001$ ).

Para finalizar, la mujer protagonista de los anuncios que muestran el estereotipo mujer agresiva (figuras 8 y 8) no refleja debilidad $(r=-0,15, p \leq 0,05)$ ni comodidad $(r$ $=-0,28, p \leq 0,001)$, y tampoco se desenvuelve en actividades de ocio $(r=-0,21, p$ $\leq 0,01)$.

\section{Conclusiones}

Tras los resultados expuestos es posible responder a las preguntas de investigación planteadas. Se puede sostener que las marcas de lujo de moda, perfume y cosmética siguen apostando por un patrón físico no inclusivo, en ocasiones manipulado

(Martínez-Oña; Muñoz-Muñoz, 2015), para representar a las mujeres que protagonizan los anuncios de sus productos. Mujeres rubias, blancas, delgadas -en algunos casos extremadamente delgadas-, de apariencia juvenil y con un rostro perfecto, desde luego no se corresponden con gran parte de la población femenina española. Si es notable un aumento en la representación de mujeres negras y mujeres de origen asiático, así como la presencia casi igualada de mujeres rubias y morenas, también es cierto que la mayoría de estas figuras femeninas aún obedece a estereotipos de belleza que continúan inamovibles. Pero no solo estos estereotipos han experimentado pocos cambios. Los estereotipos relaciona-

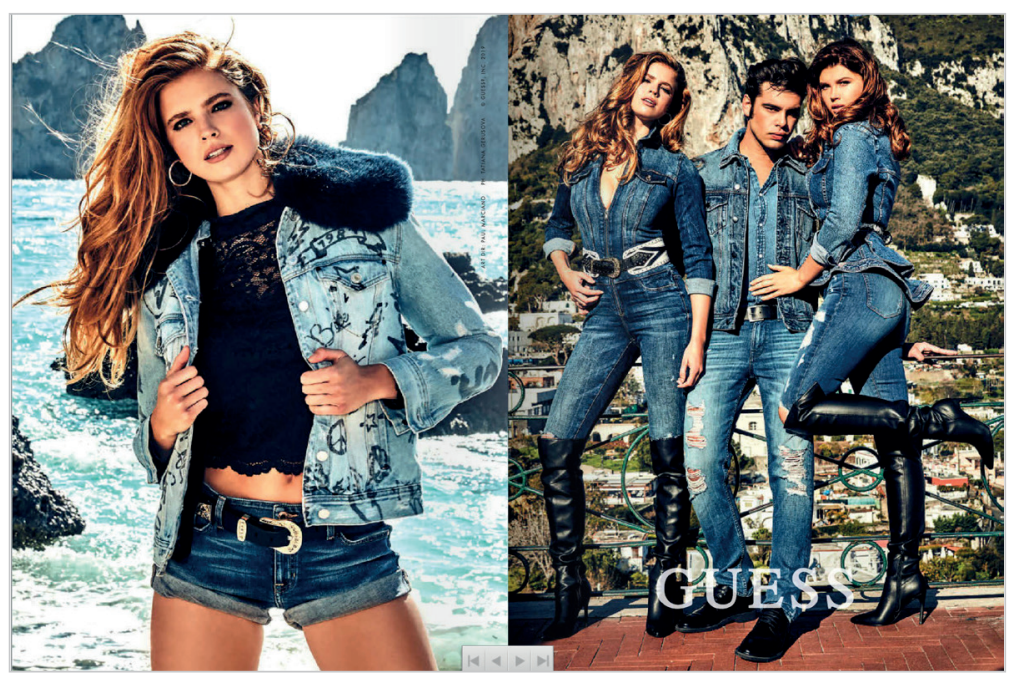

Figura 3. Mujer seductora. Fuente: revista Telva, septiembre 2019

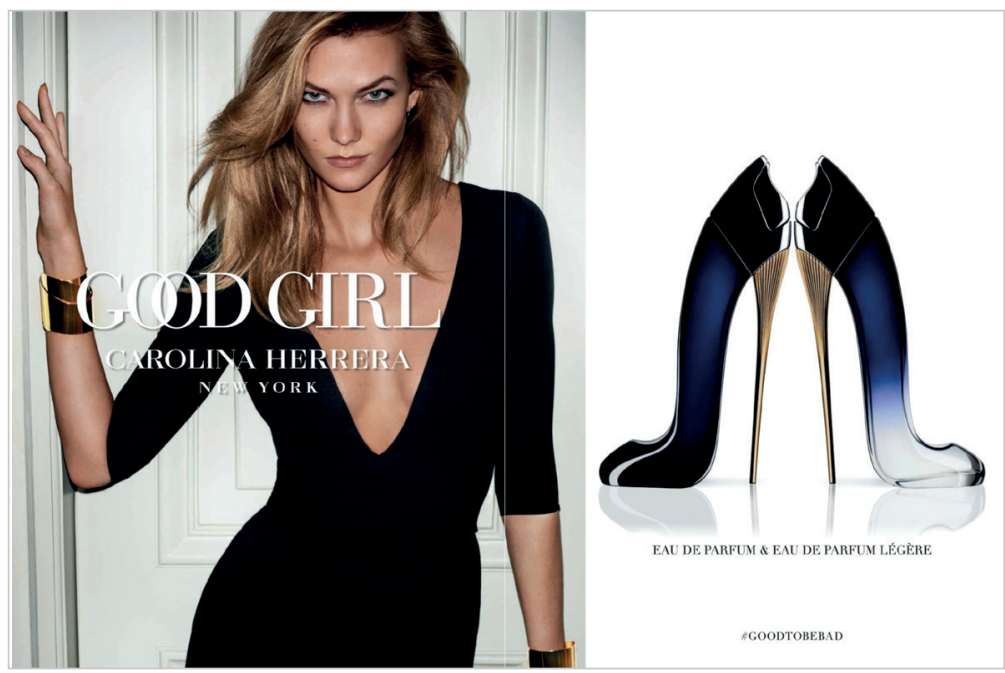

Figura 4. Mujer seductora. Fuente: revista Glamour, octubre 2019

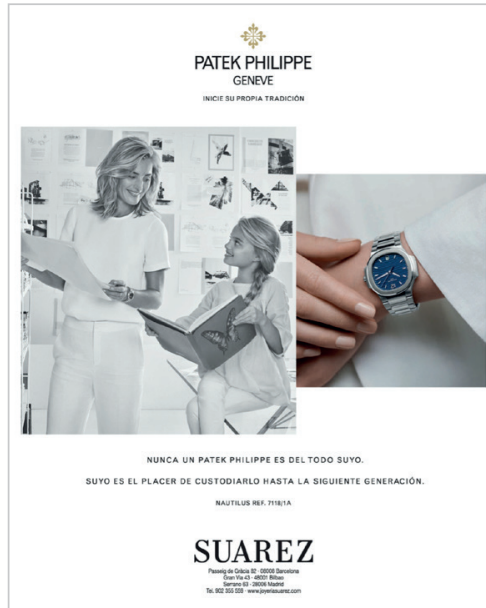

Figura 5 . Mujer familiar Fuente: revista Fi Vogue, octubre 2019

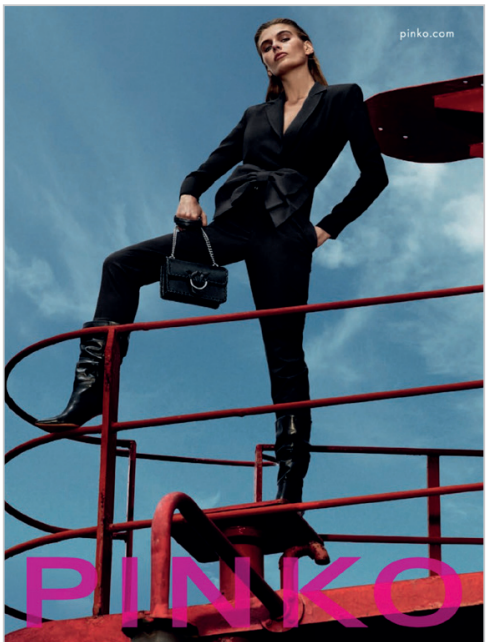

Figura 6. Mujer moderna. Fuente: revista Glamour, octubre 2019 

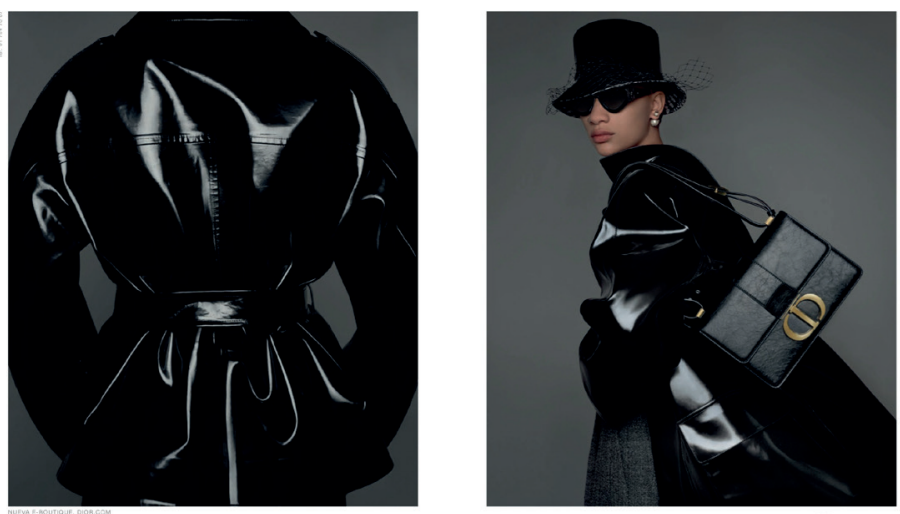

DIOR

Figura 7. Mujer agresiva. Fuente: revista Elle, octubre 2019

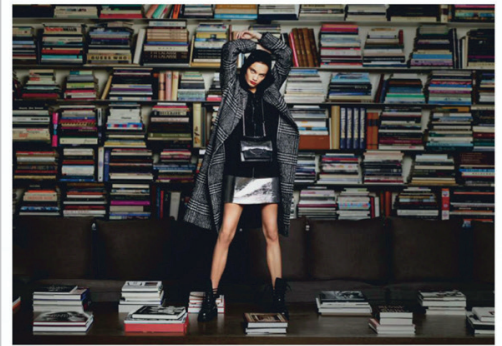

KARLLAGERFELD

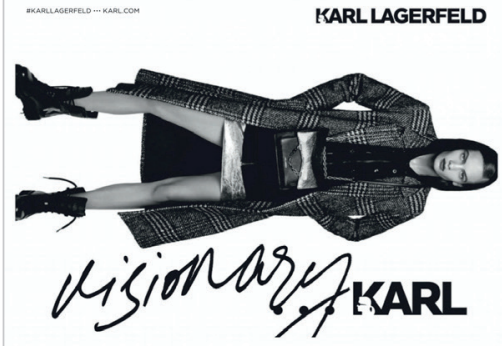

Figura 8. Mujer agresiva. Fuente: revista Vogue, septiembre 2019

dos a las actitudes y/o comportamientos han sufrido alguna alteración (ahora son seis en lugar de cuatro); no obstante, en esencia siguen siendo los mismos salvo el nuevo estereotipo mujer agresiva, el que más inquieta.

Llama la atención la separación de la mujer competitiva y con esfuerzo personal de la mujer más moderna y transgresora, puesto que hasta hace poco se integraban en una sola: la mujer moderna-transgresora. Se valora de manera positiva la existencia y el lugar de preeminencia en el conjunto de la muestra de la mujer triunfadora, porque representa valores que empoderan a las mujeres. Pero de igual manera nos preocupa que esté relacionada con una mujer entrada en años cuyo rostro y cuerpo son perfectos. Parece que las marcas de lujo de moda, perfume y cosmética intentaran decir que las mujeres más jóvenes solo deben limitarse a la seducción (mujer seductora) y a conductas conflictivas (mujer agresiva) y transgresoras (mujer moderna). El éxito, la realización personal y la faceta familiar (mujer familiar) solo es cuestión de mujeres más maduras. Desde este punto de vista, estas marcas se siguen alejando de una dimensión de la realidad fundamental para millones de mujeres en España y en todo el mundo: la vida familiar y la maternidad. Parece como si en el esfuerzo por disociar a la mujer lo más posible del hogar y del encasillamiento en el entorno familiar, se hubiera decidido minimizar su representación como madre o ama de casa. Esta tendencia debería corregirse con el paso del tiempo.

La pervivencia de una mujer alegre que manifiesta cariño hacia amigos y/o una pareja (mujer afectiva) sigue estando presente, pero en menor medida. Además, su imagen se asocia a mujeres con una complexión corporal algo más robusta. Por ende, el lenguaje publicitario de las marcas de lujo de moda, perfume y cosmética presenta contradicciones. Las mujeres pueden ser triunfadoras, cariñosas y amigables, pero no suficientemente jóvenes y delgadas. Es decir, no se terminan de ajustar por completo a los dictámenes corporales impuestos, lo que sí ocurre con la mujer seductora. En el caso de este estereotipo, el tercero más frecuente, se prolonga la exposición de una mujer sexualizada cuyo cuerpo perfecto se usa como un objeto que acompaña y potencia la compra, porque "lo bello vende" (Díaz-Soloaga; Muñiz-Muriel, 2011, p. 106).

Como se intuía, el efecto del \#metoo parece no haber conseguido erradicar o disminuir de modo relevante la presencia de una mujer sexualizada como protagonista de un anuncio. A pesar de los esfuerzos por denunciar la cosificación femenina, estas marcas insisten en presentar una mujer con una alta carga sexual y seductora, ofreciéndola como un modelo aspiracional para sus posibles consumidoras. Así pues, si bien se ha visto que en algunos aspectos hay modificaciones, todavía queda mucho trabajo hasta lograr una representación femenina más fiel a la realidad. Cuesta creer que medios de comunicación e industrias orientadas a un público mayoritariamente femenino presenten tímidos avances en el camino hacia una representación femenina más genuina.

El papel inspirador y didáctico que juegan las revistas de moda y las marcas de moda, perfume y cosmética en la vida de sus consumidoras es innegable. En lo que compete a las revistas de moda, su público recurre a ellas en búsqueda de respuestas sobre cómo vestir; cómo resultar más atractiva por fuera y por dentro; en quién buscar inspiración para conjugar las responsabilidades laborales, personales, afectivas, ciudadanas, etc., al mismo tiempo que se interesan por conocer las tendencias estéticas. Si bien es cierto que la propia naturaleza del medio (entretenimiento, evasión, ocio y descanso) complica la intencionalidad de los mensajes que albergan las revistas, también es cierto que en la sociedad actual deben asumir su enorme responsabilidad para con el conjunto de las mujeres.

Por supuesto, todos los sectores mencionados deben asumir su parte alícuota en este cambio, incluido el sistema educativo porque también propaga estereotipos (Rodríguez et al., 2016). 
En conclusión: no se trata de demonizar a las marcas de moda, perfume y cosmética, así como a las revistas de moda, sino de comprender que todos tenemos parte de responsabilidad en el esfuerzo por conseguir un cambio más efectivo y homogéneo en la sociedad. Para frenar la presencia de personajes como Jeffrey Epstein o Harvey Weinstein y sus abusos de poder, es necesario entender que la mujer no es un objeto o un mero anzuelo de consumo. La mujer es una persona con intelecto, sueños, metas, aspiraciones y belleza, con dignidad absoluta y valor individual que deben ser protegidos. No cabe duda de que movimientos como el \#metoo son necesarios para estimular la crítica y alzar la voz escondida de las mujeres que han sufrido algún tipo de abuso. No obstante, sigue flotando en el aire la cuestión sobre si las marcas y sus consumidores están realmente dispuestos y comprometidos a representar o consumir una imagen más real y fidedigna de la mujer.

\section{Nota}

1. Este artículo se presentó en formato comunicación al VII Congreso Internacional de la Asociación Española de Investigación de la Comunicación (AE-IC), Valencia, 28-30 de octubre 2020. Por un acuerdo con la $A E-I C$ fue seleccionado, revisado por pares en doble anonimato, y aprobado para ser publicado en esta revista.

\section{Referencias}

Aguaded, Ignacio; Valor-Rodríguez, Lorena (2011). "Rostros de mujer. Ludoteca interactiva sobre estereotipos femeninos en los medios". En: Jornadas universitarias La mujer en el espejo mediático, II: sexo, género y comunicación, pp. 155-168.

https://idus.us.es/bitstream/handle/11441/30655/lamujerenelespejomediatico_2.pdf

Almansa-Martínez, Ana; Gómez-de-Travesedo-Rojas, Ruth (2017). “El estereotipo de mujer en las revistas femeninas españolas de alta gama durante la crisis". Revista latina de comunicación social, n. 72, pp. 608-628.

https://doi.org/10.4185/RLCS

Andréu-Abela, Jaime (2001). “Las técnicas de análisis de contenido: una revisión actualizada”. En: Fundación Centro Estudios Andaluces, pp. 1-34.

http://mastor.cl/blog/wp-content/uploads/2018/02/Andreu.-analisis-de-contenido.-34-pags-pdf.pdf

Arriaza-Ibarra, Karen; Berumen, Regina (2019). "MeToo in Spain and France: Stopping the abuse towards ordinary women". Interactions: Studies in communication \& culture, v. 10, n. 3, pp. 169-184.

https://doi.org/10.1386/iscc.10.3.169_1

Berganza-Conde, María; Hoyo-Hurtado, Mercedes (2006). “La mujer y el hombre en la publicidad televisiva: imágenes y estereotipos". Zer: Revista de estudios de comunicación, n. 21, pp. 163-177.

https://ojs.ehu.eus/index.php/Zer/article/view/3730

Cáceres-Zapatero, María-Dolores; Díaz-Soloaga, Paloma (2008). “La representación del cuerpo de la mujer en la publicidad de revistas femeninas". Estudios sobre el mensaje periodístico, v. 14, pp. 309-327.

https://revistas.ucm.es/index.php/ESMP/article/view/ESMP0808110309A

CNN (2020). "Harvey Weinstein, condenado a 23 años de cárcel”. CNN, 11 marzo.

https://cnnespanol.cnn.com/video/harvey-weinstein-condenado-a-23-anos-de-carcel

Courtney, Alice E.; Lockeretz, Sarah-Wernick (1971). “A woman's place: An analysis of the roles portrayed by women in magazine advertisements". Journal of marketing research, v. 8, n. 1, pp. 92-95.

https://doi.org/10.2307/3149733

Díaz-Soloaga, Paloma (2007). “Valores y estereotipos femeninos creados en la publicidad gráfica de las marcas de moda de lujo en España". Anàlisi: quaderns de comunicació i cultura, n. 35, pp. 27-45.

Díaz-Soloaga, Paloma; Muñiz-Muriel, Carlos (2011). "La publicidad de moda de lujo: efectos en la autopercepción de mujeres españolas”. Indumenta: revista del Museo del Traje, n. 2, pp. 106-122.

https://en.calameo.com/read/000075335cbf6bd67101d

Díaz-Soloaga, Paloma; Muñiz-Muriel, Carlos; Quintas-Froufe, Natalia (2010a). "La imagen femenina en la publicidad gráfica de moda: un análisis longitudinal de 2002 a 2008”. Telos: Cuadernos de comunicación e innovación, n. 84, pp. 122-133.

https://www.researchgate.net/publication/260601224

Díaz-Soloaga, Paloma; Quintas-Froufe, Natalia; Muñiz, Carlos (2010b). “Cuerpos mediáticos versus cuerpos reales. Un estudio de la representación del cuerpo femenino en la publicidad de marcas de moda en España”. Icono 14, v. 8, n. 3, pp. 244-256.

https://doi.org/https://doi.org/10.7195/ri14.v8i3.237

Fernández-Poncela, Anna-María (2011). “Prejuicios y estereotipos. Refranes, chistes y acertijos, reproductores y transgresores". Antropología experimental, n. 11, pp. 317-328.

https://revistaselectronicas.ujaen.es/index.php/rae 
Gómez-de-Travesedo-Rojas, Ruth (2015). “La publicidad de Vogue en el marco de la crisis española”. Opción, v. 31, n. 6, pp. 393-411.

https://www.redalyc.org/pdf/310/31045571024.pdf

Gómez-de-Travesedo-Rojas, Ruth; Almansa-Martínez, Ana (2018). “El cuerpo de la mujer en la publicidad de las revistas femeninas de alta gama". Chasqui. Revista latinoamericana de comunicación, n. 137, pp. 315-331.

https://doi.org/10.16921/chasqui.v0i137.3165

Jaffe, Sarah (2018). "The collective power of \#MeToo". Dissent, v. 65, n. 2, pp. 80-87.

https://doi.org/10.1353/dss.2018.0031

Martínez-Oña, M. Mar; Muñoz-Muñoz, Ana M. (2015). "Iconografía, estereotipos y manipulación fotográfica de la belleza femenina”. Estudios sobre el mensaje periodistico, v. 21, n. 1, pp. 369-384.

https://doi.org/10.5209/rev_ESMP.2015.v21.n1.49100

Martínez-Rodrigo, Stella (2004). "Ambiente, figura y actio en los spots del Siglo XX". Red digital: revista de tecnologías de la información y comunicación educativas, n. 5, pp. 1-15.

http://reddigital.cnice.mecd.es/5/firmas_nuevas/informes/infor_4_ind.html

Muñoz-Saavedra, Judith (2019). “Una nueva ola feminista, más allá de \#MeToo: irrupción, legado y desafíos”. Políticas públicas para la equidad social, v. 2, pp. 177-188.

https://www.researchgate.net/publication/334481151_Una_nueva_ola_feminista_mas_alla_de_MeToo_Irrupcion_ legado_y_desafios

Navarro-Beltrá, Marián; Martín-Llaguno, Marta (2011). “El sexismo publicitario: delimitación de conceptos e indicadores de género. Estudio empírico de la producción científica”. Pensar la publicidad. Revista internacional de investigaciones publicitarias, v. 5, n. 1, pp. 51-73.

https://doi.org/10.5209/rev_pepu.2011.v5.n1.36922

Pérez-Lugo, Ana-Laura; Gabino-Campos, María; Baile, José-Ignacio (2016). “Análisis de los estereotipos estéticos sobre la mujer en nueve revistas de moda y belleza mexicanas". Revista mexicana de trastornos alimentarios, v. 7, n. 1, pp. 40-45.

https://doi.org/10.1016/j.rmta.2016.02.001

Pozzi, Sandro (2019). "Los poderosos que blindaron al pedófilo Jeffrey Epstein". El país, 25 noviembre. https://elpais.com/elpais/2019/11/22/gente/1574439088_708640.html

Rodríguez, María-Pilar; Pando-Canteli, María J.; Berasategi, Miren (2016). “¿Generan estereotipos de género los medios de comunicación? Reflexión crítica para educadores". Deusto social impact briefings, n. 1, pp. 9-35.

https://www.deusto.es/cs/Satellite/deustoresearch/en/donwload-briefing-es-en/documento?i=1340147890542

Treviños-Rodríguez, Doris; Díaz-Soloaga, Paloma (2018). “Estereotipos femeninos en anuncios gráficos de marcas de lujo de moda, perfumería y cosmética". Pensar la publicidad. Revista internacional de investigaciones publicitarias, v. 12 , pp. 145-164.

https://doi.org/10.5209/pepu.60926

Vega-Saldaña, Silvia-María; Barredo-Ibáñez, Daniel; Merchán-Clavellino, Ana (2019a). “La imagen corporal de la mujer en la publicidad gráfica de las revistas femeninas españolas de alta gama”. Anàlisi, n. 61, pp. 93-110.

https://doi.org/10.5565/rev/analisi.3194

Vega-Saldaña, Silvia-María; Barredo-Ibáñez, Daniel; Merchán-Clavellino, Ana (2019b). “Percepción de los comportamientos y patrones corporales asignados a la mujer en publicidad". Ámbitos. Revista internacional de comunicación, n. 44, pp. 162-180.

https://doi.org/10.12795/ambitos.2019.i44.10

Vega-Saldaña, Silvia-María; Barredo-Ibáñez, Daniel; Merchán-Clavellino, Ana (2020). “La identificación de las mujeres españolas con los anuncios de las revistas de alta gama”. Comunicación y género, v. 3, n. 1, pp. 61-70. https://doi.org/10.5209/cgen.67502

Zotos, Yorgos C.; Tsichla, Eirini (2014). "Female stereotypes in print advertising: a retrospective analysis". Procedia - Social and behavioral sciences, v. 148, pp. 446-454.

https://doi.org/10.1016/j.sbspro.2014.07.064 